\title{
Teachers' Social Representations of Inclusion of Children with Autism Spectrum Disorder (ASD) in Regular Class
}

\author{
Maria Alexandri \\ ORCID: 0000-0002-9577-7642 • ResearcherID: W-3121-2017 \\ Christina Papailiou \\ ORCID: 0000-0002-1789-8852 \\ Eleni Nikolaou \\ ORCID: 0ooo-0oo3-1840-3433• ResearcherID: U-2866-2017 \\ University of the Aegean, Rhodes \\ Department of Sciences of Preschool Education and Educational Design
}

Received 20 November $2017 \cdot$ Revised 25 December 2017 • Accepted 28 December 2017

\section{Abstract}

This research study aims to explore the social representations that kindergarten and first elementary class teachers have regarding the inclusion of children with Autism Spectrum Disorder (ASD) in the regular classroom. The data collection tool was a questionnaire based on previous research. The results indicate that the teachers of the present study are willing to include students with Autism Spectrum Disorders in their regular class and try to address the related difficulties. The age of the educators and their educational level do not affect their views on the inclusion of children with autism into the regular class. However, their views are influenced by their years of experience, as well as by their previous experience of working with children with autism.

Keywords: Autism Spectrum Disorders, teachers, social representations, inclusion, regular class.

\section{Introduction}

\subsection{Definition of Autism Spectrum Disorders}

The term "Autism Spectrum Disorders" refer to a group of neurodevelopmental disorders that appear in early childhood and remain throughout their life due to developmental dysfunctions of the central nervous system. These are complex disorders that affect the way the children interact with the world and the surrounding environment. Individuals with severe disorders are characterized as low-functioning individuals, while at the other end of the spectrum, there are people with milder symptoms, who are characterized as high-functioning. Children with more severe disorders may be constantly improving and progressing, but they cannot usually be self-sufficient and need constant care and supervision. The concept of spectrum indicates the existence of graduations and the variety of clinical expression. Characteristics such as different

(C) Authors. Terms and conditions of Creative Commons Attribution 4.0 International (CC BY 4.0) apply. Correspondence: Eleni Nikolaou, Dimokratias Avenue 1, 7th March Building, 85132, Rhodes, Greece. Email: enikolaou@aegean.gr. 
intelligence, varying degrees of severity of the disorder, and the degree of functionality of the individual are factors that are due to the heterogeneity of autistic spectrum and the wide variety of clinical expression. Even in the same person with autism, the picture may change depending on the age and cognitive ability of the individual (Francis, 2012).

According to DSM-IV (1994), Autism Spectrum Disorders include three disorders: autistic disorder - autism, Asperger's Syndrome and high-functioning autism.

In 2013, the revised version of DSM-IV, the DSM-V, was published, which differs in some areas from DSM-IV. Their overall diagnostic approach, however, is similar. Thus, according to DSM-V (2013), the diagnostic subcategories present in DSM-IV have been eliminated and Autism Spectrum Disorder (ASD) is considered as a diagnostic category characterized by a group of symptoms. There are now three subcategories that are differentiated based on the severity of symptoms: Level 3: "Need for Special Enhanced Support", Level 2: "Need for Enhanced Support", and Level 1: "Need to Support".

\subsection{Definition of "children with special educational needs" \\ and "inclusion of children with special educational needs"}

According to Greek law 3699/2008, children with special educational needs and disabilities are considered to be children who, for their whole life or a specific period of their school life, experience learning disabilities due to mental disability, sensory impairments regarding sight and hearing, motor disabilities, chronic irreversible health problems, speech disorders, special learning difficulties (dyslexia, dyspraxia, dyscalculia, reading disabilities), attention deficit disorder with or without hyperactivity, in developmental disorders, mental and neuropsychiatric disorders and multiple disabilities. In addition, children with special educational needs are also children experiencing cognitive, emotional and social difficulties as well as offending behavior, which may be due to abuse, domestic violence, parental neglect and abandonment. It is worth noting that the same category includes gifted children while children with low school performance attributed to external factors such as linguistic or cultural specificities are not included in the category of children with special educational needs.

The terms "abnormal, inappropriate, divergent, problematic" have been previously used to describe these children, which have now been replaced by "children with special educational needs" because they are less emotionally charged, do not promote isolation and labeling of these children and encourage their social and school inclusion (Polychronopoulou, 2008).

According to Kaiseroglou (2010), special educational needs exist when the children present difficulties, which impact their learning that require differentiation or specialization or modification of the curriculum and learning conditions in order to be appropriate and effective the education of the child.

Heward (2011) reports that children with special educational needs are those whose physical traits and learning skills vary above or below average, and thus there is a need for a personalized program, as well as related services to benefit these children. Specifically, it is argued that children with learning and behavioral problems, children with physical disabilities and sensory disorders, and also children whose mental level is so high or that they have a talent which is considered to be charismatic, need modifications in teaching in order to be able to make full use of their capabilities.

The term "inclusion" refers to the placement of a student in a regular classroom with the aim of being an organic, integral, and active member. As far as the definition of inclusion in pedagogical science is concerned, it includes pedagogical practices aimed at respecting and 
recognizing the right to diversity. It also includes providing equal educational opportunities for all children. Therefore, "inclusion" refers to the placement of children with special educational needs into the regular class and their acceptance by the other students. During the process of inclusion, children are trained by a special educator. They are not always participating, to the same extent, in the same activities as typical children. However, they interact with the rest of the children, socialize and coexist in the same class (Soulis, 2003).

\subsection{The inclusion of children with Autism Spectrum Disorders in the regular classroom}

As stated above, the basic principle of the full inclusion of children with special educational needs, and therefore children with autism, in the regular school is that all children should experience the same experiences and learn in environments that allow them to acquire new knowledge and to develop, as far as possible, their abilities, both cognitive and socio-emotional (Kourkoutas, 2011; Taffa, 1998). This right has not always been recognized equally for all children. Therefore, in 2000, the relevant legislation in our country has acknowledged that children with autism have the right to participate in the educational process, accepting thus their right to diversity (Syriopoulou-Delli, 2011). Consequently, the idea of an inclusive school for all children is gradually being promoted, with the ultimate goal of full inclusion of children with autism into the regular classroom.

It is therefore observed that students with autism tend to be increasingly placed in regular schools and classes, with the aim of social inclusion. Appropriate efforts and conditions can lead to their acceptance by their teachers and peers as well as to the gradual improvement of their cognitive and emotional abilities (Heward, 2011). The learning process, however, should take into account the potential of each student.

Regarding the teaching of children with autism in the regular class, emphasis should be placed on the interaction of children and the progressive development of their sensory, motor and cognitive abilities. The main axes of the educational process in a school, which seeks the full inclusion of children with ASD, should be the cooperation of children as well as a climate of collectivity and mutual acceptance. Furthermore, the goal of inclusion is to enable children with autism to benefit from this process and other contexts. Gradually, the engagement of children with autism in classroom activities is feasible, as well as the completion of the tasks assigned to them and the achievement of communication with teachers and their classmates. It is also important that the curriculum and the proposed activities be adapted and integrated into the needs and abilities of children with autism (Zoniu-Sideris, 2004; Taffa, 1998). In addition, a teacher should take into account the difficulties and needs of these children, ensure that the activities of the children are interesting and attract the interest of all students, so that they are intrinsically motivated to participate. Moreover, it is essential to provide children with autism the information they need in a simple way, in order to understand their environment (Vogindrukas \& Sherratt, 2005).

In this context, teachers of a regular class in which they wish to include children with autism can incorporate into their teaching imitation, which is important for learning and creating relationships with other people. They can also try to teach children with autism to keep the flow and the duration of day-to-day activities in class as well as to give children the chance to choose these activities. These activities, in fact, can be tailored to engage children with capabilities and varying abilities, through the use of preferred materials, so that children with autism can also use their abilities. They are also advised to have relatively high expectations from these children, considering that they can achieve the goals set in order to encourage them to try without, of course, being disappointed if the achievement of the above objectives is not achieved shortly. Finally, it is important that the skills the teacher will set as goals to be useful in life and everyday life of each 
child. In addition, teachers should use ordinary and everyday materials to teach children with autism in order to become familiar with their use (Heward, 2011).

Zoniou-Sideri (2004) argues that in the process of fully including children with autism into a regular class with formally developing children, there appear to be progressively small and important improvements in both the disorder itself and the performance of children. The process of learning seems to improve, and there is a gradual improvement in children's abilities, sometimes making it possible to promote them to the next class. It is expected that depending on the degree of functionality of each child and on the basis of his/her intelligence, it is sometimes necessary to take longer periods of time for children with autism to improve their school performance and their socialization skills. What is also important is the patience of the teachers and classmates, the creation of favorable conditions and the support they provide to children with ASD, thus facilitating the inclusion process. Teachers' efforts are essential to children's adaptation to school environment and to their mental health promotion (Nikolaou \& Markogiannakis, 2017a). Therefore, the full inclusion of children with autism into the regular class is not simple and easy, especially if the necessary conditions are not met and if there is not the necessary effort and will on the part of the teachers and the rest of the students. However, the inclusion of children with autism in regular schools and their co-education with formally developing children in the same class is feasible and can lead to positive and encouraging results.

According to Gena (2002), the full inclusion of children with autism into a regular class, requires that their behavior be analyzed in advance so that the necessary objectives of the teaching are gradually set. In addition, she maintains that the areas where children with autism are experiencing difficulties are those of participation, understanding of speech, inability to communicate and socialization. She also posits that children with autism have noticeable differences in their verbal communication in relation to their peers who are typically developing, as well as in understanding and speaking. However, she argues that with a systematic effort, it is likely that a significant improvement will be observed in those areas that until recently have lagged to a great extent.

\subsection{Previous research on the social representations of teachers about the inclusion of children with ASD into the regular class}

The theory of social representations was first introduced in 1961 by Moscovici and comes from Durkheim's collective representations. It is essentially a complex psychological process, which includes all the individual representations, individuals and groups, so that there is a transition from the individual to the collective level, and vice versa. Each person, according to Moscovici, shapes interactive relationships with the environment around him. As a result of it, the stimuli and the reactions shaped by the environment are incorporated into a context, the social representation. Social representations consist of two aspects, the passive, in which the image of an object is in the brain, and the energetic, where the stimuli and reactions interact and create frameworks of values, structures and concepts. In the case of the phenomenon of inclusion, social representations concern the practical thinking that is related to the understanding of the phenomenon in which the contents are organized, emerge and circulate through the continuous interactions (Michaelides, 2009).

Therefore, the study of social representations of teachers for the inclusion of children with Autism Spectrum Disorder into the regular school is particularly interesting. Initially, social representation is defined by social thinking, knowledge and views, that a group of people has on a subject, in this case, about the ASD and the phenomenon of including these children in regular schools. The exploration of social representations aims to conceive the knowledge and perceptions of teachers about the inclusion of children with ASD in the general class and the acceptance of the "different". Social representations for the inclusion of children with ASD may vary according to 
the teachers' knowledge, views and personality, the teaching method used, their behavior during the teaching process, the forms of communication they develop with the pupils, but also the forms of communication developed by the pupils themselves (Michaelides, 2009).

Humphrey \& Symes (2013) found that the perceptions of secondary school teachers about the inclusion of children with autism in the regular class have changed over the years and are more positive than before. However, few are those who feel they do not have the necessary knowledge and skills to teach children with autism. For this reason they are inclined to acquire more knowledge through training programs, thus indicating their willingness for new knowledge and specialization.

In addition, as shown by the Kimberly's study results (2008), more training results in positive attitudes towards the inclusion of children with autism in regular classes, while the increase in years of experience seems to have a negative impact on the views of primary school teachers' inclusion training.

This was confirmed and complemented by Cassady's (2011) research, in which participating primary school teachers showed particular confidence in individual education plans and agreed to tailor the courses according to students' needs and to work with their highly trained colleagues, to design appropriate programs and create the appropriate teaching environment for children with autism within a regular classroom. A prerequisite is still the proper preparation and acquisition of academic knowledge or the implementation and monitoring of compulsory training programs. Thus, teachers would have a more positive attitude towards children with autism and would be more able to manage and include them in a classroom with formally developing children.

According to Barned (2009), the knowledge of primary education teachers on autism is not shaped and not so much influenced by their studies and the limited knowledge they have gained in these studies, nor by their experience or their subject. Their perceptions about the inclusion of children with autism within a regular classroom are positive, except for cases where the pupil has severe autism and can become dangerous to himself or his classmates. They argue that if there is a special class teacher, the process of fully including the child with autism would be beneficial for both the child himself and the class as a whole.

The Gregor \& Campbell (2001) study, on the other hand, indicated that teachers who support the inclusion of students with autism into regular schools are considerably fewer than those who oppose to it. Nevertheless, those with similar experience also held more positive views. Quite a few felt that this might negatively affect typical developing students, but they did not deny to receive any training. Different conclusions are led by the Park \& Chitiyo (2010) research study, according to which teachers have a positive view of the implementation of this inclusion.

Another recent study (Rodríguez, Saldaña \& Moreno, 2012) found that primary school teachers believe that the inclusion of children with autism in regular education is a challenge for those involved, who need some support. If this support is provided, they are likely to have a positive attitude towards inclusion.

In conclusion, many research studies conducted in different countries of the world, indicate that teachers' views on the full inclusion of children with autism in their regular classroom and their co-education with formally developing children vary. In recent years, teachers' views tend to be more positive, but they do not think they have the proper knowledge, experience and support for successful inclusion. 


\section{Research methodology}

\subsection{Participants}

The participants of this research are teachers, 20 primary school teachers and 38 kindergarten teachers, in regular elementary schools and kindergartens respectively, who completed the survey questionnaire in Rhodes and Athens, Greece. More specifically, 90\% of teachers were women, while only $10 \%$ were men. $82 \%$ of them were aged $30-50$ years old. $68 \%$ of the sample were kindergarten teachers and the remaining $32 \%$ were primary school teachers. As far as the educational level of the teachers is concerned, $59 \%$ were exclusively university graduates. Regarding their years of experience, about 33\% had a experience of 11 to 15 years and $21 \%$ had a experience of 26 to 30 years. It is also worth mentioning that only 2 people, $3 \%$, had a member of their family diagnosed with autism spectrum disorders, as opposed to the rest (97\%). 90\% of the sample has not worked in a special class of a special school and 79\% has not worked in a classroom of foster teaching. Finally, with regard to the identity of the participating teachers, $59 \%$ had teaching experience with a child with autism, while the remaining $41 \%$ had no relevant experience.

\subsection{Data collection tool}

Quantitative method was used to implement this research. The data collection tool was a questionnaire, which is one of the basic techniques of the quantitative method. The questionnaire is a widespread and easy-to-use tool for collecting information and can be supplemented without the presence of the researcher in the field. It is a technique of the quantitative method, which allows the use of quantitative analyses of data collected from a large number of samples, as well as the comparison between the respondents and the answers they have given to one or more questions (Cohen, Manion \& Morrison, 2008; Zafiropoulos, 2005 ). The questionnaire used in this research was based on Michailides' research study (2009). It is a structured questionnaire, which was slightly modified to meet the purpose of the research and was administered to kindergarten teachers and primary school teachers in Athens and Rhodes. It consists of 9 closed questions, which refer to the identity of the participants, followed by 26 questions regarding the inclusion of children with special educational needs in regular classes, especially children with autism, a closed question about the type of education which they consider to be more appropriate for a child with autism and an open question for comments or remarks that the respondents may desire to make.

\section{Results}

The data collected by the answers to the questionnaires are quantitative data and therefore the SPSS statistical software was used for their analysis. In particular, the data were analyzed by descriptive statistics and then the results were compared and correlated.

Initially, the degree of agreement of teachers on the inclusion of children with autism was examined in relation to their respective views on children with intellectual disabilities and sensory disabilities. The degree of agreement was calculated by adding the scoring to the corresponding questions, while the negative questions were reversed.

According to the results, it seems that teachers agree that children with autism as well as children with sensory disabilities $(t=0.233, p=0.817$, see Table 1$)$ should be included in the regular class. However, the degree of agreement for children with intellectual disabilities is statistically significantly lower than the level of agreement for children with autism $(t=3.540, p$ $=0.001$, see Table 1 ). 
Table 1. Correlation of teachers' views on the inclusion of children with autism, sensory disabilities or cognitive disabilities in the regular class $(\mathrm{N}=58)$

\begin{tabular}{|l|c|c|}
\hline Disorder & N & Average Degree of agreement (\%) \\
\hline Autism & 58 & 62.7 \\
\hline Sensory disabilities & 58 & 62.2 \\
\hline Mental Disability & 58 & 56.8 \\
\hline
\end{tabular}

Regarding what type of class and education they consider to be more appropriate and effective, most teachers seem to consider as the most appropriate context for children with autism the regular class with the parallel provision of some kind of assistance (average $=67.8, \mathrm{~F}=6.665$, $\mathrm{p}=0.001$, see Table 2).

Table 2. Teachers' views on the most appropriate class and education for children with ASD

\begin{tabular}{|l|c|c|}
\hline $\begin{array}{l}\text { Most appropriate type } \\
\text { of class and education }\end{array}$ & $\mathrm{N}$ & Average Degree of agreement (\%) \\
\hline $\begin{array}{l}\text { Regular class with some } \\
\text { kind of help }\end{array}$ & 34 & 67.8 \\
\hline Special School & 12 & 50.3 \\
\hline $\begin{array}{l}\text { Regular class with some } \\
\text { kind of help + Special } \\
\text { School }\end{array}$ & 11 & 61.6 \\
\hline I do not know & 1 & 60 \\
\hline
\end{tabular}

Teachers' views on the inclusion of children with autism in the regular class did not differ according to their age $(F=1.386, p=0.257$, see Table 3$)$. The same applies to their educational level, as there were differences, but not statistically significant $(\mathrm{F}=1.047, \mathrm{p}=0.406$, see Table 4).

Table 3. Correlation of teachers' age with their views on the inclusion of children with autism in the regular class

\begin{tabular}{|l|c|c|}
\hline \multicolumn{1}{|c|}{ Teachers' age } & $\mathrm{N}$ & Average Degree of agreement (\%) \\
\hline $22-30$ years old & 6 & 71.7 \\
\hline 31-40 years old & 14 & 65.1 \\
\hline $41-50$ years old & 34 & 60.7 \\
\hline$>51$ years old & 4 & 60.3 \\
\hline
\end{tabular}

Table 4. Correlation of the educational level of teachers and their views on the inclusion of children with autism in the regular class

\begin{tabular}{|l|c|c|}
\hline \multicolumn{1}{|c|}{ Educational level of teachers } & N & Average Degree of agreement (\%) \\
\hline Graduate University & 34 & 63.1 \\
\hline Teaching School of Regular Education & 12 & 60 \\
\hline Teaching School of Special Education & 4 & 60.3 \\
\hline Postgraduate Studies in Special Education & 2 & 84.6 \\
\hline Seminars in Special Education & 3 & 60 \\
\hline $\begin{array}{l}\text { Teaching School of Regular Education + } \\
\text { Seminars in Special Education }\end{array}$ & 2 & 62.6 \\
\hline $\begin{array}{l}\text { Teaching School of Regular Education + } \\
\text { Postgraduate Studies in Special Education } \\
\text { + Seminars in Special Education }\end{array}$ & 1 & 66.6 \\
\hline
\end{tabular}


The answers of the teachers of the sample indicate that their views are influenced by their years of experience, since teachers with 1-5 years and 6-10 years of experience hold more positive views, as statistically significant differences were found $(\mathrm{F}=3.588, \mathrm{p}=0.007$, see Table 5).

Table 5. Correlation of teachers' years of experience and their views on the inclusion of children with autism in the regular class

\begin{tabular}{|l|c|c|}
\hline $\begin{array}{l}\text { Teachers' years } \\
\text { of experience }\end{array}$ & $\mathrm{N}$ & Average Degree of agreement (\%) \\
\hline 1-5 years & 6 & 71.7 \\
\hline 6-10 years & 6 & 78.2 \\
\hline 11-15 years & 20 & 58.6 \\
\hline 16-20 years & 6 & 65.5 \\
\hline 21-25 years & 9 & 57.4 \\
\hline 26-30 years & 11 & 60.4 \\
\hline
\end{tabular}

Finally, with regard to the past experience of teachers who participated in this research with children with autism and whether this variable affects their views on the inclusion of these children in the regular class, there were no significant statistical differences but there was a tendency the teachers with the most experience with children with autism to be more positive about the inclusion of these children in the classroom $(F=3.182, p=0.080$, see Table 6$)$.

Table 6. Correlation of the past experience of teachers with children with ASD and their views on the inclusion of children with autism in the regular class

\begin{tabular}{|l|c|c|}
\hline $\begin{array}{c}\text { Past experience of teachers } \\
\text { with children with ASD }\end{array}$ & N & Average Degree of agreement (\%) \\
\hline Answered "Yes" & 35 & 65.4 \\
\hline Answered "No" & 23 & 59.1 \\
\hline
\end{tabular}

\section{Discussion}

The aim of the present study was to study the social representations, perceptions and attitudes of kindergarten teachers and primary school teachers about the inclusion of children with ASD in the regular class. Primary school teachers and kindergarten teachers agree on the inclusion of children with ASD in the regular class, as well as on the inclusion of children with sensory disabilities. However, this is not the case with children with ASD and children with intellectual disabilities, as it seems that in this case it is more likely to accept and include in their class a child with autism than a child with a mental disability.

Regarding what type of education teachers consider as the most suitable for attending children with autism, it is noteworthy that according to their answers they consider as the most appropriate the regular classroom, while providing to them some kind of support by a counselor or a special educator (parallel support or inclusion class). The placement of these children in a special school follows and finally, there are also some participants who support one of the above forms of education, depending on the severity of autism.

It is also noted that teachers' views on the inclusion of children with autism in the regular class are not affected by their age. The same applies to their educational level, since it was noticed that even on the basis of this criterion there were no significant differences in their views.

However, teachers' years of experience affect their views, as teachers with 1-10 years of experience have more positive attitudes towards the inclusion of children with autism than 
those with more years of experience. This may be due to the fact that teachers with fewer years of experience will probably be younger. As a result, it is likely that younger teachers have received different initial academic education from older teachers and have attended more special education courses or some training programs.

The correlation of the previous experience of teachers with children with autism with their views on the inclusion of these children in the regular class, reveals that there is a tendency for teachers who have more experience with children with autism in their class to be more positive towards the inclusion of these children in a regular class.

As mentioned above, various studies have been carried out to study the views of teachers of different educational levels on the inclusion of children with ASD in regular classes. Comparing, therefore, previous research to the present study, some similarities and differences are observed. The present study indicates that teachers are in favor of including children with autism into the regular class, and also consider it important to work with their specially trained colleagues in order to help them and guide them. This finding agrees with previous research (Cassady, 2011; Park \& Chitiyo, 2010; Barned, 2009). The study of Barned (2009) has several common findings, such as the finding that teachers' views are not influenced by their studies and educational levels. In addition, Humphrey \& Symes (2013) as well as Kimberly (2008) report that the perceptions of secondary school teachers about the inclusion of children with autism in the regular class have changed over the years and are more positive than before. This is confirmed by the present research as their views are influenced by their years of experience, since teachers with fewer years of experience are more positive.

The present study contrary to previous research shows that teachers' experience plays a role in shaping their attitudes towards the inclusion of children with autism, Barned (2009) concludes that teachers are not influenced in formulating their views by their years of experience. Additionally, Gregor \& Campbell (2001) argued that teachers who favor the inclusion of students with autism in primary school are considerably fewer than those who oppose it, as opposed to the present research, where most teachers seemed to be positive for the inclusion of children with autism. The above differences are likely to be due to intercultural differences, as the countries in which each survey is conducted differ, as well as the way of life, upbringing and education of the population differs. Teachers in other countries may have a different perception and way of addressing these issues or they have a different educational system which provides for different structures and programs for the education of children with autism. Finally, it is worth mentioning that the present research differs from the aforementioned studies, as this study also examines the views of active kindergarten teachers and not just primary or secondary school teachers. The findings of the present study cannot be generalized to the general population due to the small sample size. Further research could clarify the factors that contribute to the successful inclusion of children with autism in school context.

\section{Conclusions}

In conclusion, according to the findings of this study, it is clear that the age of the educators and their educational level do not play a special role in shaping their views on the inclusion of children with autism into the regular class. However, their views are influenced by their years of experience, as well as by their experience with children with autism. It is, therefore, observed that teachers are willing, under certain conditions, to include in a regular class, the children with Autism Spectrum Disorder, in which they teach. The inclusion of a child in a regular class involves various difficulties that teachers, students with ASD and the rest members of the class may face. These difficulties constitute a challenge that teachers have to cope with so that the inclusion to become as effective as possible, both for the student with ASD and the whole class. 
The theory behind the implementation of this research is that of the inclusion philosophy. Pedagogical science is now based on the principles of inclusion. These are educational practices aimed at respecting and recognizing the right to diversity and equal education opportunities for all children without categorization and discrimination (Soulis, 2003). These pedagogical principles, moreover, concern the placement of children with special educational needs in the regular class and their acceptance by the whole educational community, teachers and other pupils. The basic principle of inclusion is therefore to remove all kinds of prejudices and to try to ensure that all children have the same learning opportunities in environments that enable them to acquire new knowledge and develop their cognitive and socio-emotional abilities, to the extent that is feasible (Kourkoutas, 2011; Taffa, 1998). Teachers perceptions affect their responses (Nikolaou \& Markogiannakis, 2017b), and therefore their positive attitudes about the inclusion of children with autism is a key factor in their adaptation to their school environment.

\section{Acknowledgements}

In this point, we would like to thank all those people who contributed to the implementation of this study. Specifically, we would like to thank all teachers, both kindergarten teachers and primary school teachers, who took part in this research study, because without their contribution it could not have been completed.

Conflicts of interest: none.

\section{References}

Barned, N. E., (2009). Attitudes of preservice teachers towards the inclusion of children with autism spectrum disorders (Master of Arts' Thesis). Jamaica: University of the West Indies.

Cassady, J. M. (2011). Teachers' attitudes toward the inclusion of students with autism and emotional behavioral disorder. Electronic Journal of Inclusive Education, 2(7).

Cohen, L., Manion, L., \& Morrison, K. (2008). The methodology of educational research. Athens: Metaichmio.

Diagnostic and statistical manual of mental disorders (4th ed.) (1994). American Psychiatric Association, Washington.

Diagnostic and statistical manual of mental disorders (5th ed.) (2013). American Psychiatric Association, Washington.

Francis, K. G. (2012). The promotion of autistic spectrum disorders (ASD) in adulthood. 2nd Psychiatric Clinic, University of Athens, Attikon General Hospital, Athens.

Gena, A. (2002). Autism and diffuse developmental disorders: Evaluation-diagnosis-treatment. Selfpublishing.

Greek Law 3699 (2008). Special education of children with disabilities or special educational needs.

Gregor, E. M. C., \& Campbell, E. (2001). The attitudes of teachers in Scotland to the integration of children with autism into mainstream schools. Autism, 5(2), 189-207.

Heward, W. L. (2011). Exceptional children. An introduction to special education. Athens: Topos. 
Humphrey, N., \& Symes, W. (2013). Inclusive education for pupils with autistic spectrum disorders in secondary mainstream schools: teacher attitudes, experience and knowledge. International Journal of Inclusive Education, 17(1), 32-46.

Kaiseroglou, N. (2010). People with special needs education in regular education schools in primary education. Issues and possibilities of exercising an internal educational policy. Thessaloniki: No publisher.

Kimberly, B., (2008). The attitudes of regular education teachers regarding inclusion for students with autism. Walden University. United States - Minnesota.

Kourkoutas, H. E. (2011). Behavioral problems in children. Interventions within family and school. Athens: Topos.

Latinopoulos, P., (2005). First steps in research: A user guide for young researchers. Athens: Kritiki.

Michaelides, T. K. (2009). Inclusive education and disability. Theoretical and empirical sociopsychological approach. Athens: Papasotiriou.

Nikolaou, E., \& Markogiannakis, G. (2017a). The role of teacher in primary school students' mental health promotion. Global Journal of Human-Social Science (A), 17(5), 22-30.

Nikolaou, E., \& Markogiannakis, G. (2017b). Greek preschool teachers' perceptions about the effective strategies for bullying prevention in preschool age. International Journal of Criminology and Sociology, 6, 172-177. DOI: https://doi.org/10.6000/1929-4409.2017.06.18

Park, M., \& Chitiyo, M. (2010). An examination of teacher attitudes towards children with autism. Journal of Research in Special Educational Needs, 11(1), 70-78.

Paschaliori, V., \& Milesi, C. (no date). The qualitative method of "participatory" observation: Highlights and reflections. Review of Educational Issues, 10.

Polychronopoulou, S. (2008). Children and adolescents with special needs and abilities. Modern trends in education and special support, Volume A. Athens: Self-publishing.

Rodríguez, I. R., Saldaña, D., \& Moreno, F. J., (2012). Support, inclusion, and special education teachers' attitudes toward the education of students with Autism Spectrum Disorders. Autism research and treatment. Departamento de Psicología Evolutiva y de la Educación, Facultad de Psicología. Spain.

Soulis, S. G. (2003). Pedagogy of inclusion, Volume A, Athens: Self-publishing.

Syriopoulou-Delli, C. K. (2011). Diffuse developmental disorders. Psychology - Pedagogy - Sociology. Athens: Grigori.

Taffa, E. (1998). Involvement of children with and without learning and behavioral problems. Athens: Ellinika Grammata.

Vogindroukas, I. \& Sherratt D. (2005). Educational guide for children with diffuse developmental disorders. Athens: Taxideftis.

Zafiropoulos, K. (2005). How is a scientific work done? Scientific research and writing. Athens: Kritiki.

Zoniou-Sideri, A. (2004). Modern accession approaches. Volume B: Practice, Athens: Ellinika Grammata. 
M. Alexandri et al - Teachers' Social Representations of Inclusion of Children

C O A $\mathbf{s}$ 